\title{
Excessive Inflammatory Response of Cystic Fibrosis Mice to Bronchopulmonary Infection with Pseudomonas aeruginosa
}

\author{
Anna van Heeckeren, Ronald Walenga, Michael W. Konstan, Tracey Bonfield, Pamela B. Davis, and Thomas Ferkol \\ Department of Pediatrics at Rainbow Babies and Childrens Hospital, Case Western Reserve University School of Medicine, Cleveland, \\ Ohio 44106-6006
}

\begin{abstract}
In cystic fibrosis (CF), defective function of the cystic fibrosis transmembrane conductance regulator (CFTR) in airway epithelial cells and submucosal glands results in chronic pulmonary infection with Pseudomonas aeruginosa. The pulmonary infection incites an intense host inflammatory response, causing progressive suppurative pulmonary disease. Mouse models of CF, however, fail to develop pulmonary disease spontaneously. We examined the effects of bronchopulmonary infection on mice homozygous for the $\mathrm{S} 489 \mathrm{X}$ mutation of the CFTR gene using an animal model of chronic Pseudomonas endobronchial infection. Slurries of sterile agarose beads or beads containing a clinical isolate of mucoid $P$. aeruginosa were instilled in the right lung of normal or CF mice. The mortality of CF mice inoculated with Pseudomonas-laden beads was significantly higher than that of normal animals: $82 \%$ of infected CF mice, but only $23 \%$ of normal mice, died within $10 \mathrm{~d}$ of infection $(P=\mathbf{0 . 0 2 3})$. The concentration of inflammatory mediators, including TNF- $\alpha$, murine macrophage inflammatory protein-2, and $K C / N 51$, in bronchoalveolar lavage fluid in CF mice $3 \mathrm{~d}$ after infection and before any mortality, was markedly elevated compared with normal mice. This inflammatory response also correlated with weight loss observed in both $\mathrm{CF}$ and normal littermates after inoculation. Thus, this model may permit examination of the relationship of bacterial infections, inflammation, and the cellular and genetic defects in CF. (J. Clin Invest. 1997. 100: 2810-2815.) Key words: Pseudomonas aeruginosa • lung • cystic fibrosis • inflammation
\end{abstract}

\section{Introduction}

In cystic fibrosis $(\mathrm{CF}),{ }^{1}$ defective function of the cystic fibrosis transmembrane conductance regulator (CFTR) in airway epithelial cells and submucosal glands results in chronic disease of the respiratory tract manifested early in life by airway obstruc-

Address correspondence to Thomas Ferkol, M.D., Division of Pediatric Pulmonology, Rainbow Babies and Childrens Hospital, Room 3001, Case Western Reserve University School of Medicine, 11100 Euclid Avenue, Cleveland, Ohio 44106-6006. Phone: 216-368-4914; FAX: 216-368-4223.

Received for publication 29 May 1997 and accepted in revised form 9 October 1997.

J. Clin. Invest.

(C) The American Society for Clinical Investigation, Inc. 0021-9738/97/12/2810/06 \$2.00

Volume 100, Number 11, December 1997, 2810-2815

http://www.jci.org tion and recurrent infections of the lung and paranasal sinuses. The CF lung is particularly susceptible to Pseudomonas aeruginosa, and this organism plays a critical role in the development and progression of pulmonary disease in CF. Individuals with $\mathrm{CF}$ acquire an endobronchial infection that elicits an intense inflammatory response. This response is characterized by a marked influx of neutrophils into the lung, and elevations in inflammatory mediators such as TNF- $\alpha$, IL-1 $\beta$, IL-6, leukotriene $\mathrm{B}_{4}\left(\mathrm{LTB}_{4}\right)$, and IL-8 (1). Neutrophils are the predominant inflammatory cell in the lungs of patients with $\mathrm{CF}$, even in individuals with mild pulmonary involvement (2). The inflammatory response in patients with $\mathrm{CF}$ appears to be excessive, and current management of pulmonary disease in $\mathrm{CF}$ is directed at the consequences of infection and inflammation (3). Moreover, some infants with CF appear to have an inflammatory response in the airways, even if infection is not detected (4).

Several hypotheses have been proposed to explain CF lung predilection for excessive inflammation and infection with $P$. aeruginosa. Some investigators suggest that the elevated salt content in the surface fluid of the $\mathrm{CF}$ airway renders human $\beta$-defensin-1 nonfunctional, eliminating the bactericidal activity of the respiratory epithelium $(5,6)$. A second hypothesis suggests that failure of the respiratory epithelial cells in the $\mathrm{CF}$ lung to ingest bacteria and be sloughed allows for $P$. aeruginosa retention at the endobronchial surface (7). A third possibility is that Pseudomonas adheres to epithelial cells in the $\mathrm{CF}$ airway in greater numbers because of the abnormal surface properties of the cells, thus leading to infection (8-10). Although details of the mechanism differ, all of these hypotheses predict that the basic defect in CF permits retention of bacteria at an otherwise sterile site, providing the stimulus for inflammation. If abnormal retention of bacteria by itself accounts for disease in the CF lung, then assuring retention of bacteria in the lung by mechanical means should eliminate the differences between the normal and CF airway. To test this hypothesis, we studied the responses of mice homozygous for the null S489X mutation and their normal littermates to instillation of agarose beads containing Pseudomonas to the airway. The histopathologic features of this animal model of chronic Pseudomonas endobronchial infection and inflammation closely mimic those present in the lungs of patients with cystic fibrosis (11). If abnormal bacterial retention accounts for excessive inflammation in $\mathrm{CF}, \mathrm{CF}$ mice and their normal littermates should respond similarly to this challenge. In fact, the $\mathrm{CF}$ mice had greater mortality. This result suggests that the $\mathrm{CF}$ genotype is associated with excessive inflammatory response compared

1. Abbreviations used in this paper: $\mathrm{BAL}$, bronchoalveolar lavage; $\mathrm{CF}$, cystic fibrosis; CFTR, cystic fibrosis transmembrane conductance regulator; EIA, enzyme immunoassay; $\mathrm{LTB}_{4}$, leukotriene $\mathrm{B}_{4}$; mip-2, macrophage inflammatory protein-2; $\mathrm{mTNF}-\alpha$, murine TNF-a. 
with the normal response, even if the initiating stimulus is similar.

\section{Methods}

Animals. Mice homozygous for the S489X (null) mutation of the CFTR and their normal littermates (wt/wt and S489X/wt) were studied $(12,13)$. The genotype of individual animals was established by polymerase chain reaction amplification of genomic DNA isolated from the animal's tail as previously described (Perkins Elmer Corp., Norwalk, CT; 14). Pups were weaned and fed a liquid elemental diet (Peptamen ${ }^{\circledR}$; Clintech Nutrition Co., Deerfield, IL) ad libitum beginning at $10 \mathrm{~d}$ of life to avoid the intestinal obstruction characteristic in mice with this mutation (14). Sterile water was available at all times for control and experimental animals. All mice were maintained in microisolator units with inedible bedding, which has been shown to reduce the frequency of intestinal obstruction (13). With these treatments, most CF mice reach adulthood and have grossly normal lungs. Fully grown, the CF mice weighed $23.7 \pm 0.7 \mathrm{~g}$, compared with $27.2 \pm 0.4 \mathrm{~g}$ for their normal littermates. Animals were studied when they were $>90 \mathrm{~d}$ of age and $>15 \mathrm{~g}$ body weight.

Experimental model of chronic P. aeruginosa infection. The agarose bead method of chronic Pseudomonas endobronchial infection developed by Cash et al. (11) and modified for mice by Starke et al. (15) was used to create chronic pulmonary infection in mice with several variations. In brief, agarose was mixed with tryptic soy broth (TSB) or TSB containing mucoid $P$. aeruginosa strain M57-15, a clinical isolate from a CF patient, and grown to late log phase. The agarose-broth mixture was added to mineral oil that was equilibrated at $50^{\circ} \mathrm{C}$, rapidly stirred for $6 \mathrm{~min}$ at room temperature, and then cooled over $10 \mathrm{~min}$. The agarose beads were washed once with $0.5 \%$ deoxycholic acid, sodium salt (SDC) in PBS, pH 7.4, once with $0.25 \%$ SDC in PBS, and four times with PBS. The beads were measured by light microscopy, and their diameter ranged from 77 to $126 \mu \mathrm{m}$. Quantitative bacteriology was performed on an aliquot of homogenized bead slurry to determine the number of CFU per $\mathrm{ml}\left(1.3 \times 10^{7} \mathrm{cfu} / \mathrm{ml}\right.$ slurry). Sterile bead preparations were confirmed to be sterile.

Mice were anesthetized with $2.5 \%$ Avertin (2\% 2,2,2-tribromoethanol $2 \%$ tert-amyl alcohol, $0.9 \% \mathrm{NaCl}$ ), placed in dorsal recumbency, and the ventral cervical area was surgically prepared. A transverse skin incision was made, and the trachea was visualized by blunt dissection. Transtracheal insertion of a $22 \mathrm{G} 1$-in catheter was used to instill $50 \mu$ l of a 1:10 dilution of the bead slurry into the right lung $(6.1 \times$ $10^{4} \mathrm{CFU} /$ mouse). The animal research protocol was reviewed and approved by the Case Western Reserve University Institutional Animal Care Committee.

Experimental protocol. In initial experiments, normal and $\mathrm{CF}$ mice underwent intratracheal injection with sterile agarose beads or beads embedded with Pseudomonas; cohorts were monitored for $10 \mathrm{~d}$ after inoculation. Animals were weighed $3 \mathrm{~d}$ after inoculation with either sterile or Pseudomonas-laden beads and daily thereafter.

In subsequent experiments, $18 \mathrm{CF}$ mice and 22 normal littermate controls were inoculated with Pseudomonas-laden beads and weighed $3 \mathrm{~d}$ aferwards. The mice were then killed by carbon dioxide narcosis and exsanguinated by cardiac puncture. The lungs were perfused with $1.0 \mathrm{ml}$ PBS via the right ventricle. Bronchoalveolar lavage (BAL) was performed by cannulating the trachea in situ with a $22 \mathrm{G} 1$ 1/2-in bead-tipped feeding needle, instilling $1.0 \mathrm{ml}$ of sterile PBS three times, and collecting the fluid by gentle aspiration. The total lavage fluid recovered from all animals was $>2.5 \mathrm{ml}$. The fluid was centrifuged for $10 \mathrm{~min}$ at $4^{\circ} \mathrm{C}$, and the supernatants were stored at $-20^{\circ} \mathrm{C}$, some aliquots with $100 \mathrm{M}$ PMSF and $5 \mathrm{mM}$ EDTA. The pellet was resuspended in $1.0 \mathrm{ml}$ PBS, and a cell count and leukocyte differential was performed. Cell counts, quantitative bacteriology, and inflammatory mediators were measured in BAL fluid by investigators without knowledge of the origin of the samples. A normal control and two CF animals died of postoperative complications; a CF mouse and a nor- mal littermate failed to receive the full bacterial inoculum because of technical problems. These animals were not included in the analysis.

Lung histopathology. After BAL, the lungs were inflation-fixed in $2 \%$ paraformaldehyde in PBS for $48 \mathrm{~h}$, and then embedded in paraffin. The lung was cut once midsagitally and embedded in paraffin. Tissue sections were cut throughout the entire tissue block such that $5-\mu \mathrm{m}$ sections were taken at regular intervals that encompassed the full craniocaudal range of sections. Sections were stained with hematoxylin and eosin using standard techniques, and were examined for histopathologic changes.

Quantitative bacteriology. The lungs and bronchi of 12 normal and $10 \mathrm{CF}$ mice inoculated with agarose beads embedded with $P$. aeruginosa $3 \mathrm{~d}$ previously were excised aseptically, homogenized in 40 $\mathrm{ml}$ normal saline ( $\mathrm{pH}$ 7.4), and samples of the lung and BAL homogenates were cultured quantitatively by serial dilution on tryptic soy agar plates (16). The upper limit of quantitation was $1.0 \times 10^{7} \mathrm{CFU} /$ $\mathrm{ml}$, which was reached or exceeded by two CF mice.

Spleens were removed and homogenized in $1.0 \mathrm{ml}$ sterile PBS. A $10-\mu l$ aliquot of the homogenate was applied to tryptic soy agar plates. Blood was also collected from all animals, and streaked on tryptic soy agar plates. The plates were incubated at $37^{\circ} \mathrm{C}$, and were inspected for $P$. aeruginosa colonies after $24 \mathrm{~h}$.

Analysis for proinflammatory cytokines in bronchoalveolar lavage fluid. Protease inhibitors were added to the BAL samples immediately after collection, and murine tumor necrosis factor- $\alpha$ (mTNF- $\alpha)$, interleukin-1 $\beta$ (mIL-1 $\beta$ ), interleukin-6 (mIL-6), murine macrophage inflammatory protein-2 (mip-2), and mouse $K C / N 51$ (KC) were measured using commercially available sandwich enzyme immunoassays (EIA) according the manufacturers' recommended protocols (R\&D Systems, Minneapolis, MN). The limits of detection for the cytokines were $5.0 \mathrm{pg} / \mathrm{ml}$. The BAL supernatants were assayed in duplicate, and the values were corrected for the respiratory epithelial lining fluid (ELF) volume recovered by measuring urea dilution (17).

Leukotriene- $B_{4}$ assay of bronchoalveolar lavage fluid. Bronchoalveolar lavage fluid was analyzed for the presence of $\mathrm{LTB}_{4}$ using a competitive EIA as previously described (Cayman Chemical Co., Ann Arbor, MI; 18). Aliquots $(100 \mu \mathrm{l})$ of BAL supernatants were evaporated by vacuum centrifugation and suspended in $100 \mu \mathrm{l}$ icecold methanol:water (1:1). To these samples, $200 \mu \mathrm{l}$ of the EIA buffer was added and assayed by standard techniques (18). The values of $\mathrm{LTB}_{4}$ were assayed in duplicate, compared with known standards, and corrected for the volume of respiratory ELF recovered.

Statistical analysis. Data are expressed as the mean \pm SEM. Data comparing the clinical status of CF mice and normal littermates were analyzed by an unpaired, two-tailed Student's $t$ test, and the relationships between the infected animal's weight loss and the inflammatory response in the lung were assessed by Pearson correlation coefficient. Fisher exact test was used to compare the survival of normal and $\mathrm{CF}$ mice after inoculation with either sterile or Pseudomonas-laden beads. Concentrations of inflammatory cells, proinflammatory mediators, and bacterial burden in the lungs of normal and CF mice were compared using a nonparametric ANOVA using the Kruskall-Wallis test (19).

\section{Results}

Growth. Fig. 1 shows the initial body weights of the CF mice and normal littermates at the onset of the experiments, and the percent change in body weight in these mice $3 \mathrm{~d}$ after inoculation with either sterile or Pseudomonas-laden agarose beads. Although the range of weights is identical for both groups, the $\mathrm{CF}$ mice were smaller than the normal animals. The $\mathrm{CF}$ mice $(n=25)$ treated with the Pseudomonas-laden beads lost significantly more weight $3 \mathrm{~d}$ after inoculation than their normal littermates $(n=51 ; P=0.0004)$. The cumulative weight loss of both $\mathrm{CF}(n=5)$ and normal mice $(n=11)$ after inoculation with sterile beads was similar. 
a

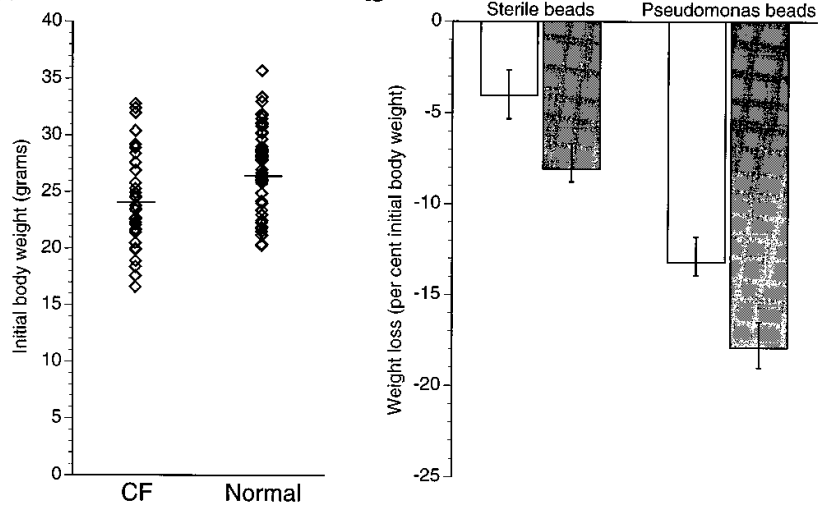

Figure 1. The clinical status of CF mice and normal littermates. (a) The adult weights attained by CF mice $(n=37)$ and normal littermates $(n=67)$ at the time of entry in the study. Data are reported as mean \pm SEM, and are compared by unpaired, two-tailed Student's $t$ test. The CF mice were smaller than their normal littermates $(P<$ 0.0001). (b) The clinical effect of endobronchial infection with $P$. aeruginosa. CF (solid columns) and normal (open columns) mice were weighed immediately before and $3 \mathrm{~d}$ after inoculation with either sterile or Pseudomonas-laden agarose beads. Control mice that were not treated, and animals that received sterile beads did not have a significant difference in weight change. Data are reported as mean \pm SEM, and are evaluated by an unpaired, two-tailed Student's $t$ test. The CF mice lost significantly more weight after inoculation with Pseudomonas-laden beads than their normal littermates $(P=$ 0.0004).

Survival. Fig. 2 illustrates the cumulative survival of mice that received sterile or Pseudomonas-laden agarose beads. The mortality of CF mice inoculated with Pseudomonas-laden beads was significantly higher than that of normal animals $(P=$ $0.023) ; 82 \%(9 / 11)$ of the infected CF mice died by $5 \mathrm{~d}$ after in-

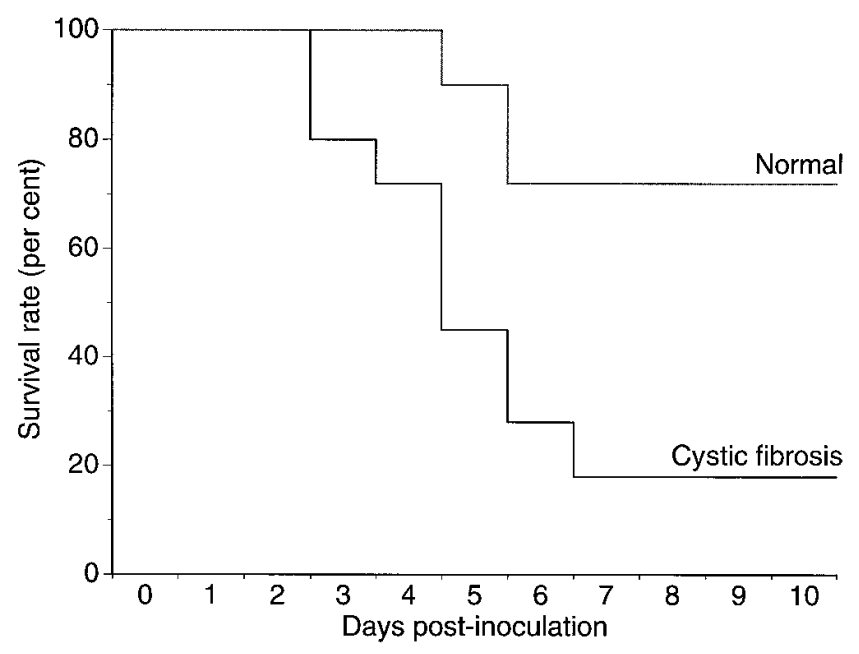

Figure 2. Mortality of CF mice $(n=11)$ and normal littermates $(n=$ 26) after intratracheal inoculation with sterile agarose beads or beads laden with $P$. aeruginosa. Mortality of infected CF mice was significantly greater than that of normal mice $(P=0.023)$. None of the CF $(n=5)$ or normal mice $(n=11)$ inoculated with sterile beads died in the $10 \mathrm{~d}$ after the procedure. fection, whereas only $23 \%(6 / 26)$ of normal mice died within $10 \mathrm{~d}$ of infection. All mice that received sterile beads survived $10 \mathrm{~d}$ after inoculation.

Pathology. The gross lung pathology of CF mice and their normal littermates $3 \mathrm{~d}$ after inoculation with $P$. aeruginosaladen agarose beads ranged from small punctate off-white nodules throughout the lung to frank consolidation of lung tissue. Histopathology sections of these mice were observed to have areas of leukocytic infiltration involving the airways, bronchus-associated lymphoid tissue, and adjacent parenchyma. Early fibrosis was evident in some of the more severely affected areas of lung (Fig. 3). Beads were seen in some airways, surrounded by neutrophils (Fig. $3 c$ ). The right lung was preferentially inoculated with the beads, but in some animals there was some pathology evident in the left lungs due to spillover from the right lung. Those mice that survived $10 \mathrm{~d}$ after Pseudomonas inoculation were observed to have milder pulmonary inflammation than those mice killed $3 \mathrm{~d}$ later. Sterile agarose beads were associated with minimal inflammation $3 \mathrm{~d}$ after inoculation into mice (data not shown).

Bronchoalveolar lavage. Bronchoalveolar lavage fluid from CF patients contains numerous neutrophils and products from the inflammatory cells. We examined cell composition in the BAL samples of normal and CF mice infected with $P$. aeruginosa. The number of inflammatory cells in the lung was markedly elevated in mice inoculated with Pseudomonas-laden
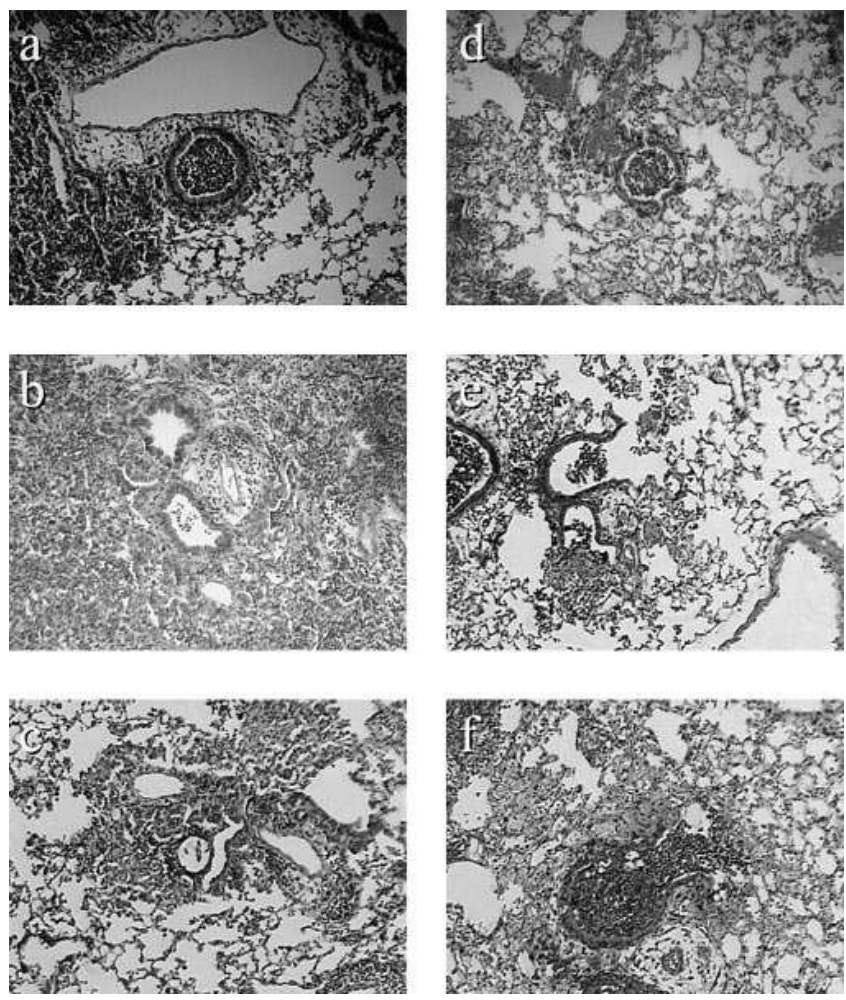

Figure 3. Histopathology of $P$. aeruginosa-infected lungs of CF and normal mice. CF null mice $(a-c)$ and their normal littermates $(d-f)$ were inoculated with $P$. aeruginos $a$-laden agarose beads and killed $3 \mathrm{~d}$ later. Lung sections from both cohorts revealed endobronchial inflammation, with associated peribronchiolar and perivascular inflammation. There also was leukocytic infiltration into the adjacent parenchyma. 


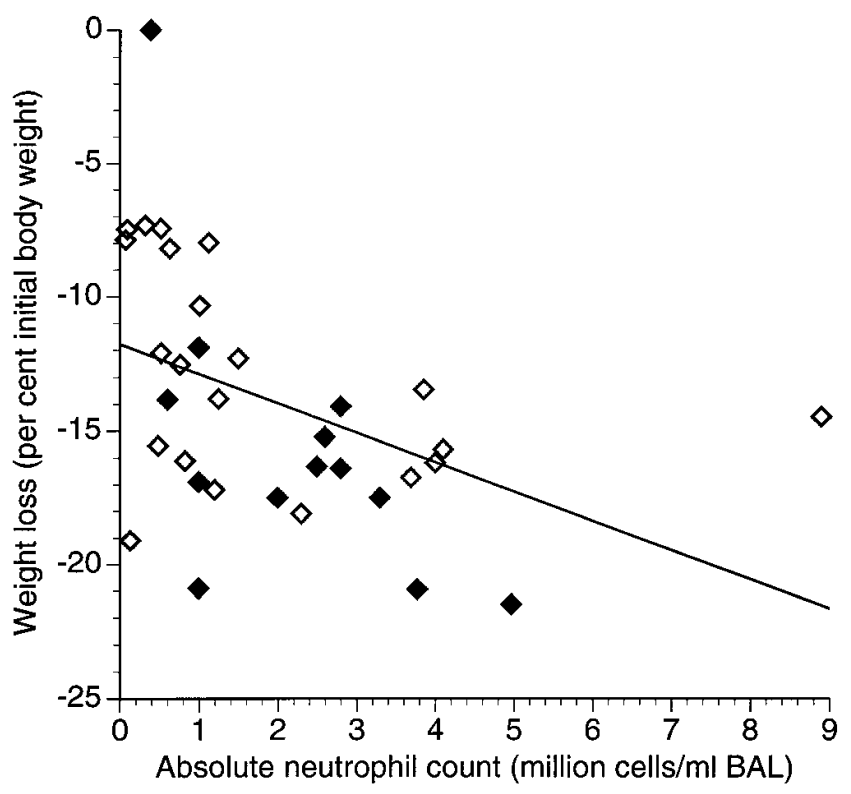

Figure 4. The relationship between the inflammatory response and clinical status of $\mathrm{CF}$ and normal mice. Inflammatory cells were collected by BAL from CF mice and normal littermates $3 \mathrm{~d}$ after inoculation with $P$. aeruginosa. Solid symbols, CF mice; open symbols, normal mice. Correlation coefficient $(r)$ of $-0.43(P<0.02)$.

beads. This inflammatory cell response correlated directly $(r=$ $-0.43, P<0.02$ ) with the weight loss of both $\mathrm{CF}$ and normal mice after inoculation with Pseudomonas-laden beads (Fig. 4). In separate experiments, there were no significant differences in cytokine and cell concentrations from BAL fluid in untreated animals and mice inoculated with sterile agarose beads (data not shown).

Infection with $P$. aeruginosa stimulates production of other inflammatory mediators, including $\mathrm{LTB}_{4}$ released predominantly by phagocytes, mTNF- $\alpha$, and mIL-1 $\beta$ (predominantly by mononuclear cells), and mIL-6 (predominantly by epithelial cells). Normalized levels of these mediators were measured in BAL samples of normal and CF mice $3 \mathrm{~d}$ after treatment with sterile or Pseudomonas-laden beads. All of the inflamma-

Table I. Inflammatory Indices in the Lungs of CF and Normal Mice 3 d After Intratracheal Inoculation with Beads Laden with $P$. aeruginosa

\begin{tabular}{|c|c|c|}
\hline & Cystic fibrosis & Normal \\
\hline & $n=14$ & $n=19$ \\
\hline Leukocytes $\left(10^{6}\right.$ cells $\left./ \mathrm{ml}\right)$ & $2.5 \pm 0.4$ & $2.2 \pm 0.6$ \\
\hline Neutrophils $\left(10^{6}\right.$ cells $\left./ \mathrm{ml}\right)$ & $2.1 \pm 0.4$ & $1.7 \pm 0.5$ \\
\hline $\mathrm{LTB}_{4}(\mathrm{ng} / \mathrm{ml})$ & $4.6 \pm 1.7$ & $2.3 \pm 0.7$ \\
\hline TNF- $\alpha$ (ng/ml) & $13.7 \pm 3.3^{*}$ & $7.3 \pm 1.7$ \\
\hline IL-1 $\beta(\mathrm{ng} / \mathrm{ml})$ & $10.8 \pm 2.3$ & $5.8 \pm 1.1$ \\
\hline IL-6 (ng/ml) & $30.3 \pm 6.0$ & $27.5 \pm 5.3$ \\
\hline $\operatorname{mip}-2(\mathrm{ng} / \mathrm{ml})$ & $32.1 \pm 7.6^{*}$ & $13.4 \pm 3.9$ \\
\hline $\mathrm{KC}(\mathrm{ng} / \mathrm{ml})$ & $11.1 \pm 2.2^{*}$ & $3.5 \pm 0.9$ \\
\hline
\end{tabular}

$P<0.05$ based on nonparametric Kruskal-Wallis ANOVA. tory mediators measured were elevated in the BAL fluid from infected CF mice compared with their infected normal littermates (Table I). In particular, the concentrations of mTNF- $\alpha$ $(P=0.049)$, mip-2 $(P=0.0078)$, and KC $(P=0.001)$ in the BAL fluid from CF mice were significantly higher than those measured in normal littermates after inoculation with Pseudomonas-laden beads. Murine IL- $1 \beta$ levels were higher in the infected CF mice, but the levels detected did not achieve statistical significance compared with infected normal mice $(P=$ 0.0535). In turn, normal mice inoculated with Pseudomonasladen beads had higher concentrations of these mediators compared with mice that were not infected or received sterile beads. By day 3 after sterile bead inoculation, only background levels of IL-1 $\beta$ and low levels of mip- 2 could be measured at all under our assay conditions, and these levels were similar for $\mathrm{CF}$ mice and their littermate controls (data not shown).

Bacteriology. Lung homogenates yielded $P$. aeruginosa in pure culture, and Fig. 5 shows the results of quantitative bacteriology of the lungs from CF $(n=10)$ and normal $(n=12)$

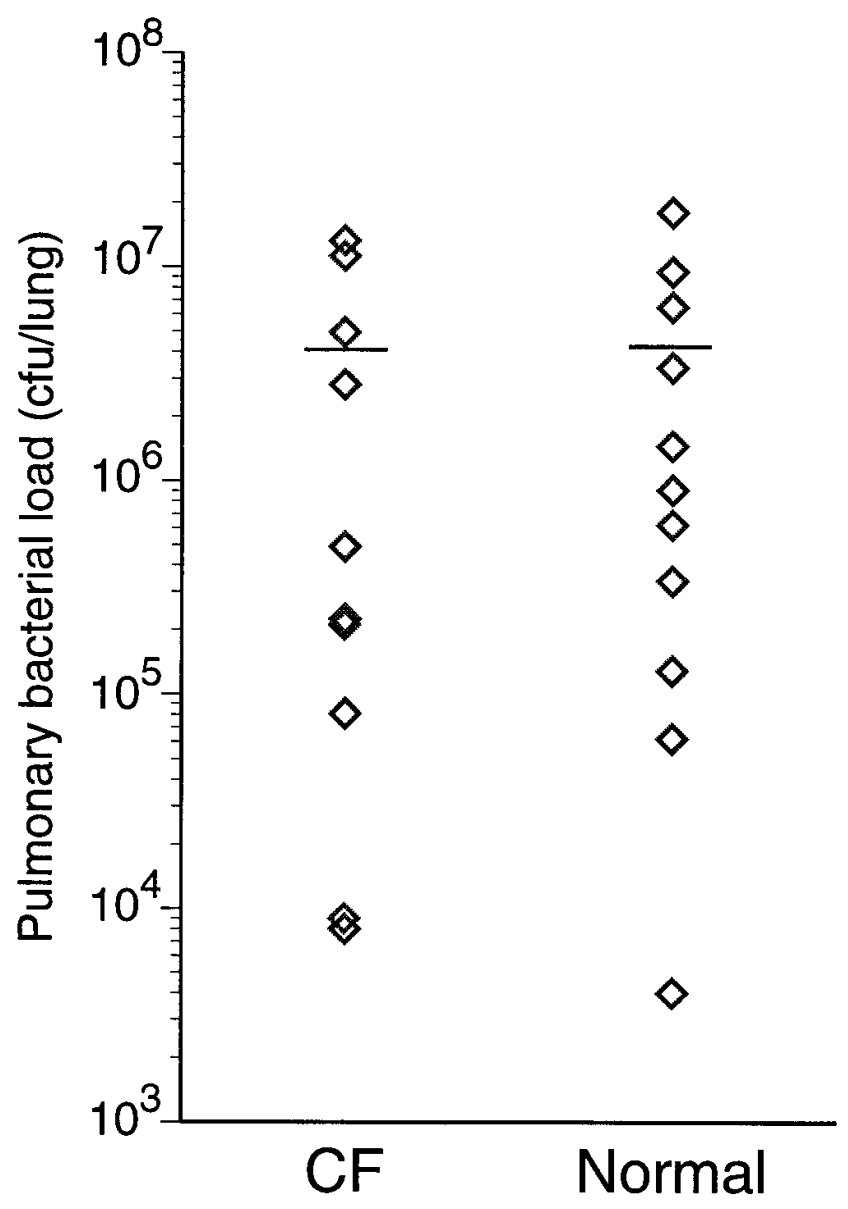

Figure 5. Bacterial burden in the lungs of $\mathrm{CF}$ and normal mice after inoculation with $P$. aeruginosa. Animals underwent intratracheal inoculation with Pseudomonas-laden beads $\left(6.8 \times 10^{4} \mathrm{cfu} / \mathrm{mouse}\right)$, and $3 \mathrm{~d}$ after treatment, bacteria was isolated from both lungs and BAL homogenates. The number of CFUs was determined by serial dilution on tryptic soy agar plates. Bacterial load in the lungs of infected normal and CF mice were compared using the Kruskall-Wallis test, and did not differ between groups. 
mice. Bacterial colony counts of $P$. aeruginosa from the lungs were similar in the $\mathrm{CF}$ mice and their normal littermates $\left(3.4 \pm 1.6 \times 10^{6}\right.$ and $3.1 \pm 1.6 \times 10^{6} \mathrm{CFU} /$ mouse, respectively). There was no growth from the blood of any mouse after inoculation with the Pseudomonas-laden beads, and only three animals-one CF mouse and two normal mice-had splenic homogenate positive for $P$. aeruginosa $3 \mathrm{~d}$ after inoculation.

\section{Discussion}

Knockout mice homozygous for the S489X mutation of the CFTR have markedly increased mortality when challenged with an intratracheal instillation of agarose beads laden with $P$. aeruginosa. The increased mortality in CF mice is associated with an increased pulmonary inflammatory response, but also with a comparable lung burden of bacteria when measured 3 days after infection (before the $\mathrm{CF}$ mice begin to die). Premature death of CF mice appears to be due to bronchopneumonia and not to sepsis, as no blood cultures and only one splenic homogenate yielded $P$. aeruginosa. Thus, it appears that the lung inflammatory response to Pseudomonas is excessive.

Animal models of $\mathrm{CF}$ do not spontaneously develop pulmonary disease. Even as CF mice are rescued from intestinal obstruction and live longer, they do not appear to be predisposed to pulmonary infection. Mice with a null mutation of the gene encoding CFTR that produce some normal protein (Edinburgh mice) have a greater probability than non-CF mice of developing infection after repeated aerosol challenges of Staphylococcus aureus or Burkholderia cepacia (20). The response of these mice to $P$. aeruginosa, the most common and distinctive pathogen in the CF lung, was not reported.

In the airways of $\mathrm{CF}$ patients, the basal potential difference across epithelia is increased, with an increased amiloride-sensitive component. Agents that elevate intracellular cyclic AMP, like forskolin or isoproterenol, fail to elicit the change in transepithelial potential difference that occurs in normal subjects (21). Tracheas removed from mice homozygous for the S489X mutation, however, have transepithelial potential difference measurements across the airway comparable to those of normal mice, including a normal chloride secretory response to treatment of the tracheal epithelial surface cyclic AMP secretagogues. This chloride secretion occurs via a calcium-regulated channel (22), for it can be inhibited by an intracellular calcium chelating agent like 1,2-bis(o-Aminophenoxy)ethane$\mathrm{N}, \mathrm{N}, \mathrm{N}^{\prime}, \mathrm{N}^{\prime}$-tetraacetic acid. It has been suggested that $\mathrm{CF}$ mice compensate for the lack of CFTR in the airways with an alternative chloride channel, and although it is uncertain whether the salt content of the epithelial lining fluid is increased in the lungs of CF mice, the relatively normal airway electrophysiology suggests that the ionic composition of the epithelial lining fluid may also be close to normal (23). Our results, however, indicate that the CF defect in these mice, insufficient to produce detectable abnormalities in airway electrophysiology or spontaneous pulmonary infections, is sufficient to produce increased morbidity and mortality when the mice are challenged with Pseudomonas. In this model, the bacteria are retained in the lung mechanically, and the model does not depend on impaired clearance of instilled bacteria by the host to establish infection. Instead, the agarose beads permit establishment of a chronic infection in both normal and $\mathrm{CF}$ mice, and produce comparable bacterial colony counts at $3 \mathrm{~d}$ in both. Thus, the in- creased mortality of the CF mice suggests that these animals have an exaggerated inflammatory response to $P$. aeruginosa.

The lungs of mice after intratracheal inoculation with the Pseudomonas-laden beads resembles the pulmonary disease characteristic of CF in many important ways. Histopathological examination of the lung shows an intense peribronchial and endobronchial inflammatory response with a lesser component of alveolar involvement, which is primarily mediated by neutrophils. Neutrophils are the prominent inflammatory cell in the lungs of patients with $\mathrm{CF}$, even in individuals with minimal pulmonary involvement (2). Animals so infected make antibodies against $P$. aeruginosa that are initially opsonic, but with time, the antibody response becomes less effective and may even be blocking. The response of animals in this model to anti-Pseudomonas vaccines and to antiinflammatory therapy is similar to that observed in patients with CF $(16,24,25)$. No animal model for the lung disease of CF is perfect, however, and the short time course over which infection and inflammation develop in the animals and the eventual decline in bacterial counts in normal animals, requiring repeated inoculations to sustain infection over a period of months, are important differences. Nevertheless, this model could illuminate the host response to chronic infection of the airways with Pseudomonas. In this model, CF mice had an increased inflammatory response $3 \mathrm{~d}$ after inoculation, but also had comparable bacterial colony counts. The pulmonary infiltrate in both normal and CF mice is predominantly neutrophilic. The remarkably high levels of proinflammatory mediators, especially chemoattractant cytokines (present in the lungs of CF mice in this model), is similar to that observed in infants and young children with $\mathrm{CF}$, even when controlled for bacterial burden (26). Proinflammatory cytokines and neutrophil markers are markedly increased in the lungs of CF mice (as in CF patients), and may perpetuate the robust inflammatory response $(4,27$, 28). Excessive pulmonary infection and inflammation have systemic effects, manifest by weight loss, and ultimately cause excess deaths of $\mathrm{CF}$ mice compared with the control animals.

In this model, $P$. aeruginosa is held in the lung by mechanical means, thus bypassing initial Pseudomonas attachment and retention. Consequently, this model does not test the ability of the animals to clear bacteria from the lung or to establish the relative importance of antibacterial factors or ingestion of bacteria in early development of pulmonary disease in CF. Rather, it permits us to examine the host response to Pseudomonas, which appears to be excessive in CF mice, and may be a critical determinant for pulmonary disease progression. These data indicate that increased inflammatory response contributes to pulmonary disease genesis, and suggest that pulmonary disease in CF may result from factors independent of the organism's impaired clearance. If the normal electrophysiology of the trachea in CF mice and their normal littermates predicts a normal salt concentration in the epithelial lining fluid, then excessive inflammation may arise independent of airway surface fluid salt content and other factors that may contribute to pulmonary disease in CF.

Although inflammation has been perceived as a response to an infectious stimulus, studies in young children with $\mathrm{CF}$ diagnosed by neonatal screening suggest some dysregulation of the inflammatory response that may be directly related to the molecular defect (4). Investigators have reported high levels of proinflammatory cytokines and neutrophils in the bronchoalveolar lavage fluid of infants with $\mathrm{CF}$, and several children had 
pulmonary inflammation even in the absence of evidence of infection (4). Thus, it is possible that inflammation may occur independent of infection, or that a relatively minor infection may induce a robust and persistent inflammatory reaction in the CF lung. Recent histopathological studies of CF mice raised in pathogen-free conditions revealed a greater number of lymphocytes in the airway submucosa compared with wildtype littermates (29). Our CF animals inoculated with sterile beads, however, did not have an excessive inflammatory or death rate.

The results of these and earlier studies suggest that at least two factors lead to the propensity of patients with CF to develop chronic endobronchial infection and inflammation: (a) retention of bacteria in the lung, and $(b)$ an intense, excessive inflammatory response to the organism. Thus, in order to understand the pathogenesis of pulmonary disease characteristic of $\mathrm{CF}$, we need to examine not only the impaired clearance of the bacteria, but also the excessive host response to $P$. aeruginosa.

\section{Acknowledgments}

The authors wish to thank Mel Berger for helpful discussions. The $P$. aeruginosa strain M57-15 was provided by Michael Tosi. We would also like to express our appreciation to Elizabeth Eckman and Calvin Cotton for their assistance in this project, and to Dave Fletcher, Jay Hilliard, Chris Statt, Frank Mularo, Mike Haley, Jerry Chipuk, and Sheri Miller for providing their expert technical support.

This study was supported by National Institutes of Health grants DK49003, DK27651, and DK48996, and a Research Development Program Grant from the Cystic Fibrosis Foundation.

\section{References}

1. Konstan, M.W., and M. Berger. 1993. Infection and inflammation of the lung in cystic fibrosis. In Cystic Fibrosis. P.B. Davis, editor. Marcel Decker, Inc., New York, New York. pp. 219-276.

2. Konstan, M.W., K.A. Hilliard, T.M. Norvell, and M. Berger. 1994. Bronchoalveolar lavage findings in cystic fibrosis patients with stable, clinically mild lung disease suggest ongoing infection and inflammation. Am. J. Respir. Crit. Care Med. 150:448-454.

3. Ramsey, B.W. 1996. Drug therapy: management of pulmonary disease in patients with cystic fibrosis. N. Eng. J. Med. 335:179-188.

4. Khan, T.Z., J.S. Wagener, T. Bost, J. Martinez, F.J. Accurso, and D.W. Riches. 1995. Early pulmonary inflammation in infants with cystic fibrosis. Am. J. Respir. Crit. Care. Med. 151:1075-1082.

5. Smith, J.J., S.M. Travis, E.P. Greenberg, and M.J. Welsh. 1996. Cystic fibrosis airway epithelia fail to kill bacteria because of abnormal airway surface fluid. Cell. 85:229-236.

6. Goldman, M.J., G.M. Anderson, E.D. Stolzenberg, U.P. Kari, M. Zazloff, and J.M. Wilson. 1997. Human $\beta$-defensin-1 is a salt-sensitive antibiotic in lung that is inactivated in cystic fibrosis. Cell. 88:553-560.

7. Pier, G.B., M. Grout, T.S. Zaidi, J.C. Olsen, L.G. Johnson, J.R. Yankaskas, J.B. Goldberg, and J.B. Goldberg. 1996. Role of mutant CFTR in hypersusceptibility of cystic fibrosis patients to lung infections. Science. 271:64-67.

8. Saiman, L., G. Cacalano, D. Gruenert, and A. Prince. 1992. Comparison of adherence of Pseudomonas aeruginosa to respiratory epithelial cells from cystic fibrosis patients and healthy subjects. Infect. Immun. 60:2808-2814.

9. Saiman, L., and A. Prince. 1993. Pseudomonas aeruginosa pili bind to asialoGM1, which is increased on the surface of cystic fibrosis epithelial cells. $J$. Clin. Invest. 92:1875-1880.

10. Tang, H., M. Kays, and A. Prince. 1995. Role of Pseudomonas aeruginosa pili in acute pulmonary infection. Infect. Immun. 63:1278-1285.

11. Cash, H.A., D.E. Woods, B. McCullough, W.G. Johanson, and J.A Bass. 1979. A rat model of chronic pulmonary infection with Pseudomonas aeruginosa. Am. Rev. Respir. Dis. 119:453-459.

12. Snouwaert, J.N., K.K. Brigman, A.M. Latour, N.N. Malouf, R.C Boucher, O. Smithies, and B.H. Koller. 1992. An animal model for cystic fibrosis made by gene targeting. Science. 257:1083-1088.

13. Clarke, L.L., B.R. Grubb, S.E. Gabriel, O. Smithies, B.H. Koller, and R.C. Boucher. 1992. Defective epithelial chloride transport in a gene-targeted mouse model of cystic fibrosis. Science. 257:1125-1128.

14. Eckman, E., C. Cotton, D. Kube, and P.B. Davis. 1995. Dietary changes improve survival of CFTR S489X homozygous mutant mouse. Am. J. Physiol. 269:L625-L630.

15. Starke, J.R., M.S. Edwards, C. Langston, and C.J. Baker. 1987. A mouse model of chronic pulmonary infection with Pseudomonas aeruginosa and Pseudomonas cepacia. Pediatr. Res. 22:698-702.

16. Konstan, M.W., K.M. Vargo, and P.B. Davis. 1990. Ibuprofen attenuates the inflammatory response to Pseudomonas aeruginosa in a rat model of chronic pulmonary infection: implications for antiinflammatory therapy in cystic fibrosis. Am. Rev. Respir. Dis. 141:186-192.

17. Rennard, S.I., G. Basset, D. Lecossier, K.M. O'Donnell, P. Pinkston, P.G. Martin, and R.G. Crystal. 1986. Estimation of volume of epithelial lining fluid recovered by lavage using urea as a marker of dilution. J. Appl. Physiol. 60:532-538.

18. Konstan, M.W., R.W. Walenga, K.A. Hilliard, and J.B. Hilliard. 1993 Leukotriene $\mathrm{B}_{4}$ markedly elevated in the epithelial lining fluid of patients with cystic fibrosis. Am. Rev. Respir. Dis. 148:896-901.

19. Zar, J.H., editor. 1974. Biostatistical Analysis. Prentice-Hall, Englewood Cliffs, New Jersey

20. Davidson, D.J., J.R. Dorin, G. McLachlan, V. Ranaldi, D. Lamb, C Doherty, J. Govan, and D.J. Porteous. 1995. Lung disease in the cystic fibrosis mouse exposed to bacterial pathogens. Nat. Genet. 9:351-357.

21. Knowles, M.R., M.J. Stutts, A. Spock, N. Fischer, J.T. Gatzy, and R.C Boucher. 1983. Abnormal ion permeation through cystic fibrosis respiratory epithelium. Science. 221:1067-1070.

22. Grubb, B.R., A.M. Paradiso, and R.C. Boucher. 1994. Anomalies in ion transport in CF mouse tracheal epithelium. Am. J. Physiol. 267:C293-C300.

23. Clarke, L.L., B.R. Grubb, J.R. Yankaskas, C.U. Cotton, A. McKenzie, and R.C. Boucher. 1994. Relationship of a non-cystic fibrosis transmembrane conductance regulator-mediated chloride conductance to organ-level disease in CFTR (-/-) mice. Proc. Natl. Acad. Sci. USA. 91:479-483.

24. Pier, G.B., G.J. Small, and H.B. Warren. 1990. Protection against mucoid Pseudomonas aeruginosa in rodent models of endobronchial infections. Science. 249:537-540.

25. Pennington, J.E., W.F. Hickey, L.L. Blackwood, and M.A. Arnaut 1981. Active immunization with lipopolysaccharide Pseudomonas antigen for chronic Pseudomonas bronchopneumonia in guinea pigs. J. Clin. Invest. 68: $1140-1148$.

26. Noah, T.L., H.R. Black, P.W. Cheng, R.E. Wood, and M.W. Leigh 1997. Nasal and bronchoalveolar lavage fluid cytokines in early cystic fibrosis. $J$. Infect. Dis. 175:638-647.

27. Balough, K., M. McCubbin, M. Weinberger, W. Smits, R. Ahrens, and R. Fick. 1995. The relationship between infection and inflammation in the early stages of lung disease from cystic fibrosis. Pediatr. Pulmonol. 20:63-70.

28. Armstrong, D.S., K. Grimwood, R. Carzino, J.B. Carlin, A. Olinsky, and P.D. Phelan. 1995. Lower respiratory infection and inflammation in infants with newly diagnosed cystic fibrosis. Br. Med. J. 310:1571-1572.

29. Zahm, J.-M., D. Gaillard, F. Dupuit, J. Hinnrasky, D. Porteus, J.R Dorin, and E. Puchelle. 1997. Early alterations in airway mucociliary clearance and inflammation of the lamina propria in CF mice. Am. J. Physiol. 272:C853C859. 